\title{
Empowerment and its Relation with the Job Performance Among the Bank Employees in the Kingdom of Bahrain
}

\author{
Neda Abdulkarim Albaqqali ${ }^{1}$ and Jayendira Sankar ${ }^{2}$ \\ ${ }^{1}$ MBA Student, College of Administrative and Financial Sciences, AMA International University, Bldg 829, Road 1213, Blk \\ 712, Salmabad, P.O. Box 18041, KINGDOM OF BAHRAIN \\ ${ }^{2}$ Assistant Professor, College of Administrative and Financial Sciences, AMA International University, Bldg 829, Road 1213, \\ Blk 712, Salmabad, P.O. Box 18041, KINGDOM OF BAHRAIN \\ ${ }^{2}$ Corresponding Author: jpsankar@amaiu.edu.bh
}

\begin{abstract}
Empowerment of employees give them the power and responsibility in order to enhance their self-confidence and give them freedom to perform well. The performance of employees is the final product sought by all organizations, which is an indicator for success and failure. The primary objective of this study is to assess the extents of empowerment and the level of job performance among the bank employees in the Kingdom of Bahrain and if there is a significant correlation between both variables. The descriptive study was based on surveying 250 employees and managers from 5 main banks in Bahrain. The questionnaire measured the empowerment level as well as the job performance level among the respondents and the correlation between them. As considered the main two variables of the study. The survey questionnaire was developed and modified by the researcher according to the scope of the study. The response rate was $80 \%$. The study data and hypotheses were examined by statistical analysis done on SPSS 25.0. Most of the respondents found that the level of empowerment and job performance were at very high level in banks in Bahrain. The study found a strong correlation between empowerment of employees and job performance. Thus, the alternative hypothesis was accepted. The findings support the high level of empowerment of employees and job performance and there is a strong correlation between them.
\end{abstract}

Keywords-- Empowerment, Job Performance, Bahrain Empowerment, Bahrain Bank Employees

\section{INTRODUCTION}

It is the active participation of the staff in the management of their organizations in decision-making, problem solving, creative thinking, disposition, responsibility, and control of results. Successful management creates great interest in their employees and their jobs, so that they feel as if they have the organization they work in. This is what some call psychic property and therefore its success from its success and failure. Human resources are the most important asset of the organization, which must be exploited efficiently and provide the appropriate empowerment environment, which enables the employee in practice to perform its role efficiently, which contributes to improving performance and productivity, gaining customer satisfaction and increasing the organizational effectiveness of the organization.

Empowerment aims to give workers the powers and responsibilities and enhance their self-confidence and give them the freedom to perform the work according to the way they see fit without the intervention of direct management. The importance of empowerment is that it enhances the self-responsibility of the employee, which makes the work of the employee is consistent with the organizational objectives of the institution, which contributes to the maintenance of quality. And ultimately achieve the desired goals. The performance of employees is the final product sought by all organizations, which is an indicator of the performance of the organization and failure, and the upgrading of the level of performance of employees depends on several factors affecting them, including: environmental factors, and personal and functional.

The problem of research is the existence of some problems and negatives, as a result of the central orientation, the hierarchy of empowerment levels, the multiplicity thereof, the length of official lines of communication, and the confidentiality of information reaching some employees. This has made it necessary to study the empowerment of Bahrain Bank employees and its impact on the performance of Bahrain Bank employees, Empowerment has become the core of the administrative creativity of any administrative organization, including the banking sector, and management scientists agree that contemporary organizations live in changing and complex circumstances, making their need for creativity an urgent need. Managers who manage modern administrative organizations must and to develop the capabilities of the workers to contribute to solving problems, participate in decision-making, and generate new ideas and work in the spirit of one team outstanding and serious to the creative work. 
This study intends to evaluate the empowerment and its relation with the job performance among the bank employees in the kingdom of bahrain. Also,

1. To examine the extent of empowerment that the bank has provided to their employees in the Kingdom of Bahrain in terms of delegation of authority, participation, communication, team work.

2. To identify the level of job performance of the banks employees in the Kingdom of Bahrain in terms of delegation of authority, participation, communication, team work.

3. To analyze the significant relationship between the empowerment and level of job performance of bank employees in the kingdom of Bahrain.

4. To bring out the problems encountered and recommendations in terms of empowerment among the bank employees in the kingdom of Bahrain.

Indranil (2018) concluded that, the employee empowerment and its impact on employee performance is one of the widely researched areas in business management. In the contemporary corporate environment, same has become more prominent due to growing importance of large scale corporate restructuring, creation of autonomous work teams and other significant developments happening around. Banking and service industries have witnessed large scale transformation and the role of employee empowerment has become a common endeavour across the globe. However, in the countries like UAE, which has a fast growing and robust financial sector experimenting with new developments and practices and employing one of the highest diverse workforce not only in Asia, but also in the entire banking world; employee empowerment has become a more complicated and challenging task. Improvement in employee performance through employee empowerment has therefore become a strategic essentialities.

Lee (2017) study examines the relationship between enabling leadership and performing tasks. Specifically, we propose a curved relationship between enabling leadership and performing employee tasks. Furthermore, by applying a leadership emergency perspective, we suggest that the correlative relationship between command leadership and employee performance is supervised through the employee learning orientation. Using survey data from 137 delegates, our results show that the U-shaped inverse relationship between the leadership of empowerment and the performance of employee tasks is supervised by the employee's learning orientation. The effects of theory and process are discussed. Although leadership empowerment is generally considered a desirable approach to leadership, its effectiveness has been questioned and the response mixed. By integrating the effect of a lot of good thing and handling dual tasks.
Ukil (2016) through the study, the impact of employee empowerment on employee satisfaction, quality of service and the impact of employee satisfaction on quality of service. The results of the statistical analysis reveal the satisfaction of the staff and the service quality depends heavily on the employee's empowerment, and satisfied employees provide better quality services. The results of this research have clear implications for both staff and organizations. This study suggests that by empowering employees, the organization can increase the level of employee satisfaction which leads to higher quality of service.

Shahrani (2015) believed that, expanding the powers of employees and enriching their knowledge, knowledge and skills to refine their expertise and develop their capacity to participate in decision-making and implementation in normal and emergency conditions, with the aim of raising their performance in work and facing problems. We can say from the above that there is a common consensus between the different definitions of empowerment that we have touched upon. All of them emphasize the importance of empowering employees to participate in decision-making and the need to acquire and share the knowledge and information they need through training and development of their abilities and knowledge.

Hagras \& Melhem (2014) brought out from their study that, the strategy of empowerment in achieving the functional excellence of the employees of the Ministry of Interior in the Kingdom of Bahrain, and to clarify the importance of the issue of empowerment and its role in achieving functional excellence as it is one of the most able strategies to provide the resources with a high degree of flexibility and speed in meeting the needs of customers. It is found that there is high level of empowerment of employees in the Ministry of the Interior in Bahrain, high level of job excellence among employees of the Ministry of Interior in Bahrain, and there are difficulties faced by workers in order to distinguish them by work.

\section{RESEARCH METHODOLOGY}

The study utilized the descriptive - evaluative type of research. An organizationally - based descriptive portion of design was pursued through the use of relevant data via conducting questionnaire. The total sample of the study is 250 respondents with 50 BISB Bank employees, 50 Ithmaar Bank employees, 50 Baraka Bank employees, 50 NBB Bank employees and 50 Ahli United Bank employees. The population of each will be $20 \%$ BISB Bank employees, $20 \%$ Ithmaar Bank employees, 20\% Baraka Bank employees, 20\% NBB Bank employees and 20\% Ahli United Bank employees.

The research instrument that was used in this study is a self-made questionnaire, these questionnaires were 
distributed to two hundred (250) employees in the Kingdom of Bahrain. The weighted mean was utilized to identify the average perception of the respondents. T-test was used to calculate the difference in the perception of the respondents. The correlation assessed whether the means of two groups are statistically different from each other among the bank employees in the Kingdom of Bahrain.

\section{RESULTS AND DISCUSSIONS}

The analysis and interpretation of result related to the empowerment and its relation with the job performance among the bank employees in the kingdom of bahrain. The research study appraised the extent of empowerment that the bank has provided to their employees in terms of delegation of authority, participation, communication, team work, the level of job performance of the banks employees in terms of delegation of authority, participation, communication, team work, the significant relationship between the empowerment and level of job performance of bank employees, and the problems encountered and recommendations in terms of empowerment by the bank employees in the kingdom of Bahrain.

\begin{tabular}{|c|c|l|}
\hline SCALE & RANGE & \multicolumn{1}{|c|}{ DESCRIPTION } \\
\hline 5 & $4.20-5.00$ & Strongly Agree \\
\hline 4 & $3.40-4.19$ & Agree \\
\hline 3 & $2.60-3.39$ & Moderately Agree \\
\hline 2 & $1.80-2.59$ & Disagree \\
\hline 1 & $1.00-1.79$ & Strongly disagree \\
\hline
\end{tabular}

Majority of the respondents were males (80\%). In terms of age category, $60 \%$ of the respondents lie in the age category (36-45 yrs old). The researcher found that most of the respondents $(60 \%)$ had an experience of 5-10years and $70 \%$ had above the standard qualification. The vast majority of the respondents were $81 \%$ employees while minority was managers who marked just $19 \%$ out of the total sample.

The respondents' age category was divided by age into four categories: the age group (Less than 25 years), the age group ( 25 to 35 years), the age group (36 to 45 years) and finally (45 and over). The majority (60\%) of the study respondents was in the age category of 36-45 years old, while $20 \%$ in the range of 26-30 years old and $10 \%$ similarly for both age categories less than 25 years old and more than 45 years old respectively. As shown in Figure 4, the highest percentage of banks operating in the Kingdom of Bahrain in the age group (36-45 years) represents the highest percentage of the sample.

The study respondents are divided according to experience in three categories: the first category (less than 5 years) and the other two categories respectively (from 5 to 10 years) and (10 years and more). The majority of respondents (60\%) had 5-10 years' experience and those less than 5 years marked $26 \%$ while those more than 10 years' experience were just $14 \%$. It is obvious from Figure 5 that the highest proportion of employees in Bahrain's banks has a level of experience of 5 to 10 years, from the research sample. This ratio is sufficient to indicate that the level of experience of Bank staff is satisfactory. $70 \%$ of the study respondents were qualified above the average, while $20 \%$ were just highly qualified and just $10 \%$ were postgraduates. The result indicates that the highest ratio is the Qualified above average that represents the highest proportion of the research sample. It could also indicates that majority of the of banks' employees in Bahrain are qualified above the average.

The respondents were distributed according to the level of the job to two categories: the class (Employee), and then class (Manager). A vast majority of $81 \%$ respondents were in the position of employees while only $19 \%$ were in manager positions. That shows that the highest proportion of employees in the banks of Bahrain in the level of career (Employee), and they represent the highest proportion of the research sample.

The high level of empowerment of the employees of the banks of the kingdom of Bahrain, where the mean of the total empowerment variable reached (4.26) indicating a result of far above the standard, which indicates the high level of empowerment among the respondents of the study from both the employees and managers of the banks of Bahrain. The respondents also perceived that empowerment is far above the standards in terms of delegation of authority and team work scoring means of 4.42 and 4.37 respectively. On the other hands, the respondents found that empowerment is just above the standard in terms of participation and communication scoring means 4.12 and 4.11 respectively. It was also clear from the results that the most important factors in the empowerment of Bahrain Bank employees are in the following order from the highest score: the Delegation of Authority (4.42), Team Work 4.37, Participation 4.12, and Communication 4.11.

In terms of delegation of authority, the majority of respondents found that The Central Bank of Bahrain Authority authorizes the decision-making authority of all the empowerment levels of the Bank is far above the standards. With respect to the participation, the majority of respondents found that The Bank's management opens the door for employees to participate in strategic decision making is also far above the standard. However, majority of the respondents also found that the bank's management 
allows communication with all employees to explain their positions was far above the standard. Finally in terms of team work, the respondents believe that all staff members are given equal opportunities to express their views was also found to be far above the standard.

The high level of performance of employees of the banks of the kingdom of Bahrain, where the ratio of the calculation of the change in the performance of workers total (4.44), which indicates the high level of employees in the sample of respondents working in the banks of the kingdom of Bahrain. In terms of delegation of authority, most of the respondents found it far above the standards when it comes to positive contribution in helping others accomplish their work. Also the majority found it far above standards when it comes to participation in terms of communication, the respondents believe that it is far above the standards when it comes to getting the information needed to get the job done anytime they want. Finally, most of them agree that the team work atmosphere is flexible and rated it as far above the standards. The most important dimension in the dimensions of the performance of employees is (Participation) at mean of 4.5 , and then the other three dimensions in the level of performance of employees in the banks of Bahrain that were scored means similarly are Delegation of authority, Communication and Team Work. Generally speaking the job performance scored far above the standards in all dimensions.

\begin{tabular}{|c|c|c|c|c|c|}
\hline \multirow[t]{2}{*}{ Variables } & Correlation & \multirow{2}{*}{$\begin{array}{c}\text { Delegation Of } \\
\text { Authority }\end{array}$} & \multirow[t]{2}{*}{ Participation } & \multirow[t]{2}{*}{ Communication } & \multirow[t]{2}{*}{ Team Work } \\
\hline & Sig & & & & \\
\hline \multirow{2}{*}{$\begin{array}{l}\text { Delegation Of } \\
\text { Authority }\end{array}$} & Correlation & & 0.597 & 0.415 & 0.513 \\
\hline & Sig & & 0.000 & 0.000 & 0.000 \\
\hline \multirow[t]{2}{*}{ Participation } & Correlation & 0.535 & & 0.447 & 0.468 \\
\hline & Sig & 0.000 & & 0.000 & 0.000 \\
\hline \multirow[t]{2}{*}{ Communication } & Correlation & 0.369 & 0.339 & & 0.469 \\
\hline & Sig & 0.000 & 0.000 & & 0.000 \\
\hline \multirow{2}{*}{ Team Work } & Correlation & 0.685 & 0.664 & 0.468 & \\
\hline & $\mathrm{Sig}$ & 0.000 & 0.000 & 0.000 & \\
\hline
\end{tabular}

Source: Primary Data

The results of the previous table show that there is a strong correlation between the empowerment of employees and the performance of employees in the banks of Bahrain at a level of correlation of (0.702) at the level of
(0.000). Thus rejecting the imposition of nihilism and accepting the alternative provision that provides for a link between the empowerment of workers and their performance in the banks of Bahrain.

\begin{tabular}{|l|l|l|}
\hline Variables & Correlation & \multirow{2}{*}{ Job Performance } \\
\cline { 2 - 2 } & Sig & \\
\hline Empowerment & Correlation & $\mathbf{0 . 7 0 2}$ \\
\hline & Sig & $\mathbf{0 . 0 0 0}$ \\
\hline
\end{tabular}

\section{Source: Primary Data}

Through the above the researcher description of the procedures followed by the researcher in the implementation of the study, and the definition of study methodology, description of the study population, and determine the study sample, and the preparation of the study tool (questionnaire), and to ensure validity and reliability, and the statement of the study procedures, statistical methods used in the treatment of results.

\section{CONCLUSION}

Empowerment aims to give workers the powers and responsibilities and enhance their self-confidence and give them the freedom to perform the work according to the way they see fit without the intervention of direct management. The performance of employees is the final product sought by all organizations, which is an indicator of the performance of the organization and failure, and the upgrading of the level of performance of employees depends on several factors affecting them, including: environmental factors, and personal and functional. The results of the study showed a good response rate to the survey questionnaire and the respondents generally perceived very high level of empowerment and job performance. That was declared majorly by the male factor as $80 \%$ were responding males who were mainly employees rather than manager. The results showed that the employees were highly empowered by the banks were they are 
employed and this was manifested thru 4 important factors: delegation of authority, team work, participation and communication. Also it was obvious from the results that those respondents showed a very high level of job performance at work in four important dimensions: delegation of authority, team work, participation and communication. The researcher found a strong correlation between the empowerment of employee and job performance in the banks of Bahrain. Thus accepting the alternative hypothesis that provides a link between the empowerment of workers and their performance in the banks of Bahrain confirming that there is a strong correlation.

\section{RECOMMENDATION}

The need to emphasize the acceptance of responsibility positively by the bank leaders and give them sufficient authority with the availability of motivation material and moral and seek to achieve their satisfaction, translating empowerment into actual practices, giving the bank leaders a sense of the meaning of their functions and sense of competence and their ability to control the methods of work and results, the need to build the mature empowerment personality of the leadership based on honesty and self-confidence and others, provide effective communication within departments to access information between all levels of leadership, the necessary training for all leaders to help them to successfully implement the empowerment and assume the additional responsibilities for their jobs, the necessity of designing the leadership, empowerment and organizational functions of the bank leadership, the need to focus on the concept of change and the role of the leader as a call for change and responsible for the management of major changes in response to changes in the surrounding climate and develop its ability to deal with the manifestations of resistance to change around, expanding the use of self-management teams in the banks of Bahrain, adoption of the concepts of delegation and transfer of power and participation and decentralization as modern concepts of total quality management and empowerment, to consolidate the culture of empowerment of the leaders of the banks in Bahrain, this is an effective mechanism to ensure the participation of the leaders in developing their performance and acquiring the necessary expertise and capacities to enable them, effective implementation of the principle of decentralization of management and rehabilitation of leaders to become selfable and professionally to manage their own colleges, and the need to work to develop awareness and knowledge of the concept of empowerment of workers from.

\section{REFERENCES}

[1] Fernandez, S. \& Moldogaziev, T. (2015). Employee empowerment and job satisfaction in the US Federal Bureaucracy: A self-determination theory perspective. The American review of public administration, 45(4), 375-401.

[2] Gong, Y., Wang, M., Huang, J. C., \& Cheung, S. Y. (2017). Toward a goal orientation-based feedback-seeking typology: Implications for employee performance outcomes. Journal of Management, 43(4), 1234-1260.

[3] Hagras, A. M. C. \& Melhem, A. P. (2014). Empowerment strategy and its impact on achieving functional excellence in the worlds in the ministry of the interior in the kingdom of Bahrain: A field study. (Unpublished master thesis). Gulf University, Bahrain.

[4] Indranil Bose. (2018). Employee empowerment and employee performance: An empirical study on selected banks in UAE. Journal of Applied Management and Investment, 7(2), 71-82.

DOI: 10.13140/RG.2.2.23260.69765.

[5] Kirkman, B. L., Rosen, B., Tesluk, P. E., \& Gibson, C. B. (2004). The impact of team empowerment on virtual team performance: The moderating role of face-to-face interaction. Academy of Management Journal, 47(2), 175192.

[6] Laschinger, H. K. S., Finegan, J. E., Shamian, J., \& Wilk, P. (2004). A longitudinal analysis of the impact of workplace empowerment on work satisfaction. Journal of Organizational Behavior, 25(4), 527-545.

[7] Lee, S., Cheong, M., Kim, M., \& Yun, S. (2017). Never too much? The curvilinear relationship between empowering leadership and task performance. Group \& Organization Management, 42(1), 11-38.

[8] Shahraani, Abdullah Awad (2015). Role of empowerment in achieving sports activities. Master Thesis, Naif Arab University for Security Sciences.

[9] Ukil, M. I. (2016). The impact of employee empowerment on employee satisfaction and service quality: empirical evidence from financial enterprizes in Bangladesh. Business: Theory and Practice, 17(2), 178189. 